\title{
Developing an alternative alcohol advertising complaint review system: lessons from a world- first public health advocacy initiative
}

\author{
Hannah L Pierce ${ }^{a, c}$, Julia M Stafford ${ }^{a}$ and Mike Daube ${ }^{b}$ \\ ${ }^{a}$ McCusker Centre for Action on Alcohol and Youth, Curtin University, Perth, WA, Australia \\ ${ }^{b}$ Faculty of Health Sciences, Curtin University, Perth, WA, Australia \\ c Corresponding author: hannah.pierce@curtin.edu.au
}

\section{Article history}

Publication date: July 2017

Citation: Pierce HL, Stafford JM, Daube M. Developing an alternative alcohol advertising complaint review system: lessons from a world-first public health advocacy initiative. Public Health Res Pract. 2017;27(3):e2731729. https://doi.org/10.17061/phrp2731729

\section{Key points}

- The Alcohol Advertising Review Board (AARB) is an alternative complaint review service that uses community engagement, media advocacy and communication with policy makers to encourage effective regulation of alcohol advertising

- The AARB's approach could be replicated where there is a need to strengthen regulation of advertising that contributes to poor public health outcomes, including for unhealthy food and gambling

\begin{abstract}
Young people in Australia are frequently exposed to alcohol marketing. Leading health organisations recommend legislative controls on alcohol advertising as part of a comprehensive approach to reduce alcohol-related harm. However, Australia relies largely on industry self-regulation.

This paper describes the development and implementation of the Alcohol Advertising Review Board (AARB), a world-first public health advocacy initiative that encourages independent regulation of alcohol advertising. The AARB reviews complaints about alcohol advertising, and uses strategies such as media advocacy, community engagement and communicating with policy makers to highlight the need for effective regulation. In 4 years of operation, the AARB has received more complaints than the self-regulatory system across a similar period. There has been encouraging movement towards stronger regulation of alcohol advertising.

Key lessons include the importance of a strong code, credible review processes, gathering support from reputable organisations, and consideration of legal risks and sustainability. The AARB provides a unique model that could be replicated elsewhere.
\end{abstract}




\section{Introduction}

Children and young people in Australia are frequently exposed to alcohol promotions through traditional media including television, print and outdoor - and more targeted forms including social media, product placement and event sponsorship.' Many alcohol promotions contain features that would be expected to appeal to young people. ${ }^{2}$

Systematic reviews of longitudinal research have indicated that exposure to alcohol advertising influences young people's beliefs and attitudes about drinking, and increases the likelihood that adolescents will start to use alcohol or will drink more if they are already using alcohol. ${ }^{3}$

Controls on alcohol advertising are recognised as an essential feature of the comprehensive approach required to reduce alcohol-related harm. ${ }^{1,4,5}$ In Australia, as in other countries, restrictions on alcohol advertising mainly exist through industry self-regulation ${ }^{6}$, although no evidence exists that self-regulation is effective at curbing alcohol promotion. ${ }^{7}$ Leading health organisations, including the World Health Organization, recommend legislated frameworks to reduce young people's exposure to alcohol advertising. ${ }^{1,4,5}$

This paper describes the development and implementation of a world-first advocacy initiative to encourage independent regulation of alcohol advertising. It also summarises lessons that can guide other countries seeking stronger advertising regulation.

\section{Alcohol advertising regulation in Australia}

Regulation of alcohol advertising content rests largely with the alcohol and advertising industries. ${ }^{8}$ The Advertising Standards Bureau (ASB) assesses complaints against the Australian Association of National Advertisers (AANA) Code of ethics ${ }^{9}$ and the Code for advertising and marketing communications to children. ${ }^{10}$ Alcohol advertising complaints are also assessed by the Alcohol Beverages Advertising Code (ABAC) Scheme against an alcoholspecific code of practice.

Regulation of the placement of alcohol advertising is incomplete and inconsistent. The Commercial television industry code of practice restricts alcohol advertisements to $8.30 \mathrm{pm}-5$ am and $12 \mathrm{pm}-3 \mathrm{pm}$ on weekdays, and $8.30 \mathrm{pm}-5$ am on weekends and school holidays on free-to-air channels. ${ }^{11}$ An exemption allows alcohol advertisements during sports programs on weekends and public holidays. ${ }^{11}$ An Outdoor Media Association guideline limits outdoor alcohol advertising to outside a 150-m sight line of a school gate, except in the vicinity of a licensed venue. ${ }^{12}$ Placement of alcohol advertising in other media is unrestricted.

Weaknesses in the self-regulatory system include that code provisions are narrowly worded ${ }^{13}$ and important forms of marketing are not covered, including sponsorship. ${ }^{14}$
There appear to be no sanctions for advertisers breaching codes, decisions by the ABAC and ASB are not directly enforceable, and there is no monitoring function..$^{13}$ There is also strong representation of vested interest groups within the schemes. The three ABAC Scheme Directors represent the Brewers Association of Australia and New Zealand, the Distilled Spirits Industry Council of Australia and the Winemakers' Federation of Australia..$^{15}$ These groups jointly fund the ABAC Scheme and form the majority of its Management Committee. ${ }^{16}$ The ABAC Adjudication Panel includes two health academics. However, concerns have been raised about limitations of the ABAC code and processes $^{13}$ that may constrain the influence of health expertise on determinations. The alcohol industry is represented on the AANA Board.

Although health groups, researchers and advocates have drawn attention to the weaknesses of the selfregulatory system and called for action, and despite high levels of public concern ${ }^{17}$, Australian governments have done little to strengthen alcohol advertising regulation.

\section{Development of an alternative complaint review system}

Public health advocacy has contributed to policy change in areas such as tobacco control. ${ }^{18}$ Two Western Australian (WA) health organisations, the McCusker Centre for Action on Alcohol and Youth, and the Cancer Council WA, supported by national and local groups, recognised the need for a more substantial, well-planned advocacy approach to alcohol advertising regulation. From October 2010 to March 2012, a Steering Committee comprising representatives from both organisations with experience in public health advocacy guided development of the Alcohol Advertising Review Board (AARB), a service that would accept and review complaints about alcohol advertising in Australia, independent of vested interests.

The project aimed to highlight the volume of alcohol advertising and weaknesses of the self-regulatory system. The longer-term objective was to motivate Australian governments to implement legislative controls on alcohol advertising.

\section{AARB code}

The Steering Committee developed a code covering all forms of alcohol marketing, with a focus on protecting children and young people. A young person was defined as under 25 years, consistent with evidence regarding the impact of alcohol on the developing brain ${ }^{19}$ and the ABAC provision that alcohol advertisements must not depict adults younger than 25 years. ${ }^{14}$

The AARB content code was developed using existing provisions from self- or quasi-regulatory codes in Australia, New Zealand, the UK and Canada (specific code provisions are described elsewhere ${ }^{20}$ ). The incorporation of provisions 
already accepted by the alcohol and advertising industries minimised their ability to oppose the code.

Because few existing codes regulate the placement of alcohol advertising, the Steering Committee developed placement provisions based on what would reasonably minimise young people's exposure and the National Preventative Health Taskforce recommendation to "phase out alcohol promotions from times and placements which have high exposure to young people aged up to 25 years". ${ }^{5}$ Provisions cover television, radio, cinema, publications, outdoor, public transport, internet and sponsorship. A general provision captures new forms of media.

\section{Review panel}

The Steering Committee invited individuals from fields including research, medicine, public health, law, education, social services and marketing to be (unpaid) review panel members. The AARB has more than 100 panel members to ensure the review process is not burdensome. Panel members are asked to review complaints no more than once a month and contribute to the extent they are able. To ensure independence, panel members must not be current employees of, or accept funding from, the alcohol industry. Panel members' identities are confidential due to concerns they may be targeted by those who oppose the AARB's objectives.

\section{Procedures}

Procedures were developed to ensure the review process was responsive to complainants and sought action from advertisers where appropriate. One full-time position at the McCusker Centre for Action on Alcohol and Youth manages the AARB, referring to the Steering Committee for guidance.

Complaints are received by email, an online form, phone or post. Anyone can submit complaints, including the Steering Committee. On receipt of a complaint, the advertiser is notified and invited to respond within 7 working days. Complaints are then sent electronically to three panel members who consider and assess the advertisement with regard to the code. Determinations are decided by simple majority vote. The advertiser and complainant are notified of the determination. Where relevant, the advertiser is requested to modify or remove the advertisement. The AARB has no enforcement powers and supports the case for statutory controls on alcohol advertising.

\section{Launch}

Professor Fiona Stanley AC, a leading child-health researcher and former Australian of the Year, was invited to chair the AARB. The AARB was launched in March 2012 by Professor Stanley and other prominent public health figures, with support from a range of organisations.

\section{Industry response}

The AARB immediately gained industry attention - six alcohol and advertising industry groups released media statements opposing its establishment. After notifying advertisers of initial complaints, the AARB received a similar template letter from major alcohol companies and retailers operating in Australia. It appears that alcohol companies, which are usually fiercely competitive, pursued a cohesive strategy to respond to the AARB. These reactions indicate that, despite industry groups publicly seeking to downplay the significance of the AARB, its potential impact caused concern. This was further demonstrated when ASB representatives attended a 2015 AARB event at Parliament House in Canberra without invitation, despite there being no regular contact between the AARB and ASB or ABAC. Alcohol and advertising industry groups have continued to publicly criticise the AARB and defend the self-regulatory system. ${ }^{21,22}$

\section{Advocacy strategies}

The Steering Committee identified all levels of government as advocacy targets. The Australian Government has overarching responsibility for advertising regulation. State, territory and local governments may control some aspects, including placement of advertising on public transport.

Media advocacy and community engagement are tools used to influence policy makers. ${ }^{18}$ The AARB mobilises the community to monitor alcohol advertising and actively encourages individuals to express their concerns.

The AARB attracts regular media coverage through strategic and opportunistic advocacy to highlight different issues. This includes a focus on areas not covered by industry processes, and promotions to which young children have been exposed. The release of AARB reports provides opportunities for strategic coverage and engagement with policy makers. For example, two annual reports were released at Parliament House in Canberra, supported by politicians from all major parties. Opportunistic media coverage is generated for specific advertisements that demonstrate the weaknesses of selfregulation. The AARB has attracted substantial coverage in national media, advertising, trade and health publications. ${ }^{23}$

The AARB and other organisations regularly use AARB materials to engage policy makers through correspondence and in meetings.

\section{Outcomes and impact}

In 4 years of operation, the AARB received more complaints and produced more determination reports than the much longer-established ABAC Scheme across a similar period (Table 1).

A range of offending advertisements and campaigns have been removed or modified. Although the major multinational alcohol companies formally declined to participate in the AARB process, on numerous occasions 
Table 1. Comparison of AARB and ABAC Scheme activity

\begin{tabular}{lcc}
\hline & $\begin{array}{c}\text { AARB activity, } \\
\text { March 2012 to } \\
\text { March 2016 }\end{array}$ & $\begin{array}{c}\text { ABAC Scheme } \\
\text { activity, 2012-2015 } \\
\text { calendar years }{ }^{24,25}\end{array}$ \\
\hline $\begin{array}{l}\text { Number of complaints } \\
\text { received }\end{array}$ & 768 & 507 \\
$\begin{array}{l}\text { Number of } \\
\text { determinations }\end{array}$ & 128 \\
$\begin{array}{l}\text { Number of } \\
\text { determinations that } \\
\text { upheld complaints } \\
\text { (at least in part) }\end{array}$ & 509 & 26 \\
$\begin{array}{l}\text { Number of } \\
\text { determinations that } \\
\text { dismissed complaints }\end{array}$ & 483 & \\
\hline
\end{tabular}

$\mathrm{AARB}=$ Alcohol Advertising Review Board; $\mathrm{ABAC}=$ Alcohol

Beverages Advertising Code

a The number of determinations is lower than the number of complaints received for a range of reasons, including that multiple complaints were received for the same advertisement, a copy of the advertisement could not be accessed or the subject of the complaint was outside the scope of the AARB.

they (and others) have removed or modified advertisements after receiving AARB communications.

Governments have also responded. Following the release of a 2016 AARB report calling for governments to remove alcohol advertising from public transport, the South Australian Government announced that it would implement this measure from mid-2017 ${ }^{26}$, and the Western Australian Government, elected in early 2017, has committed to removing alcohol advertising from all public buses, bus stops and train stations. ${ }^{27}$ Evidence and/or recommendations provided by the AARB were cited in both announcements. ${ }^{26,27}$

The AARB has amassed a substantial complaints database that has become a valuable source of information for public health researchers and advocates. The Steering Committee uses the database to identify areas of community concern to inform priority areas for action and develop policy recommendations. Information from the database and determination reports has been accessed for external research projects ${ }^{28}$ and provided to Australian health organisations to support advocacy work.

\section{Replicating the AARB approach elsewhere}

Addressing young people's exposure to alcohol advertising has been identified as a public health priority internationally ${ }^{29}$, but opposition from vested interests has been a factor in delaying effective regulation in some countries. ${ }^{30,31}$ There may be a role for an alternative advertising complaint review process in other countries to encourage governments to introduce regulatory frameworks, including in addressing other forms of marketing, such as for unhealthy food and gambling. Based on the experience of the AARB, the recommendations in Box 1 may assist others in developing similar approaches.

Box 1. Recommendations for developing an alternative advertising complaint review system

\section{Develop a strong code}

The foundation of an advertising review process is a strong code that improves on the weaknesses of selfregulatory codes, has the wellbeing of young people as its primary objective and is comprehensive in its coverage of marketing strategies.

\section{Have a credible process}

Maintaining a strong but fair position by providing advertisers with the opportunity to respond to complaints and administering review processes meticulously as well as in a timely manner gives credibility to the process.

\section{Gather support}

Support from reputable and influential health, community and other organisations maximises advocacy efforts. Supporting groups can help to build awareness and mobilise their networks to participate in advocacy activities. A united approach from organisations across sectors adds strength to calls for action.

\section{Consider legal risks}

A well-planned approach to considering and managing legal risks will minimise the possibility of challenges from well-resourced vested interest groups. Involving appropriate legal expertise in the development of the project may be valuable.

\section{Consider sustainability}

Policy change can be a protracted process, and generating innovative ideas for advocacy activities and regular contact with policy makers encourages continued interest in the issue. The sustainability of advocacy activities should be considered to support ongoing impact. It is possible to operate a complaint review process with a modest budget; costs may include staffing, communications and producing reports. 


\section{Conclusion}

Moves to curb alcohol promotion will inevitably take time, and are fiercely resisted by a powerful global industry. The AARB is an innovative approach that draws attention to concerns about advertising self-regulation and communicates the need for independent regulation of unhealthy advertising. There have already been noticeable impacts, including the removal of advertisements and moves by state governments towards stronger regulation. Because significant impacts of advocacy can occur out of public view and across extended time periods ${ }^{17}$, the AARB's true effect is expected to be even greater than what has already been observed. The approach may be relevant for other countries seeking government action to address marketing practices that are contrary to public health objectives.

\section{Acknowledgements}

The authors would like to thank and acknowledge Cancer Council WA, Rebecca Johnson and Professor Simone Pettigrew for their contribution to the development of the $A A R B$. The AARB and the research in this article received funding from the McCusker Charitable Foundation.

\section{Competing interests}

None declared

\section{Author contributions}

All authors contributed to the development and implementation of the AARB. HP and JS were responsible for designing and drafting the manuscript. All authors contributed to writing, editing and reviewing the manuscript.

\section{References}

1. Australian Medical Association. Alcohol marketing and young people: time for a new policy agenda. Canberra: AMA; 2012 [cited 2017 Jun 7]. Available from: ama.com.au/ sites/default/files/documents/alcohol_marketing_young_ people.pdf

2. Chen M, Grube J, Bersamin M, Waiters E, Keefe D. Alcohol advertising: what makes it attractive to youth? J Health Commun. 2005;10(6):553-65.

3. Jernigan D, Noel J, Landon J, Thornton N, Lobstein T. Alcohol marketing and youth alcohol consumption: a systematic review of longitudinal studies published since 2008. Addiction. 2017;112 Suppl 1:7-20.

4. World Health Organization. Global strategy to reduce the harmful use of alcohol. Geneva: WHO; 2010 [cited 2017 Jun 7]. Available from: www.who.int/substance_ abuse/msbalcstragegy.pdf
5. National Preventative Health Taskforce. Australia: the healthiest country by 2020. National preventative health strategy - the roadmap for action. Canberra: Commonwealth of Australia; 2009 [cited 2017 Jul 12]. Available from: www.health.gov.au/internet/ preventativehealth/publishing.nsf/Content/CCD7323311E3 58BECA2575FD000859E1/\%24File/nphs-roadmap.pdf

6. Noel J, Lazzarini Z, Robaina K, Vendrame A. Alcohol industry self-regulation: who is it really protecting? Addiction. 2017;112 Suppl 1:57-63.

7. Moodie R, Stuckler D, Monteiro C, Sheron N, Neal B, Thamarangsi $\mathrm{T}$, et al. Profits and pandemics: prevention of harmful effects of tobacco, alcohol, and ultra-processed food and drink industries. Lancet. 2013;381(9867):670-9.

8. Advertising Standards Bureau. Canberra: ASB. Alcohol advertising; 2016 [cited 2016 Dec 5]; [about 2 screens]. Available from: adstandards.com.au/products-issues/ alcohol-advertising

9. Australian Association of National Advertisers. AANA code of ethics. Sydney: AANA; 2012 [cited 2017 Jun 1]. Available from: aana.com.au/content/uploads/2014/05/AANA-Codeof-Ethics.pdf

10. Australian Association of National Advertisers. AANA code for advertising and marketing communications to children. Sydney: AANA; 2014 [cited 2017 Jun 1]. Available from: aana.com.au/content/uploads/2014/05/AANA-Code-ForMarketing-Advertising-Communications-To-Children.pdf

11. Free TV Australia. Commercial television industry code of practice. Sydney: Free TV Australia; 2015 [cited 2017 Jun 7]. Available from: www.freetv.com.au/media/ Code_of_Practice/Free_TV_Commercial_Television_ Industry_Code_of_Practice_2015.pdf

12. Outdoor Media Association. OMA alcohol advertising guidelines. Sydney: OMA; 2016 [cited 2017 Jun 7]. Available from: www.oma.org.au/_data/assets/pdf_ file/0003/13449/OMA_Alcohol_Guidelines_2016_Update. pdf

13. Australian National Preventive Health Agency. Alcohol advertising: the effectiveness of current regulatory codes in addressing community concern. Canberra: Commonwealth of Australia; 2014 [cited 2017 Jun 7]. Available from: www.fare.org.au/wp-content/uploads/ Alcohol-Advertising-Final-Report-30-April-2014.pdf

14. The ABAC Scheme Limited. ABAC responsible alcohol marketing code. Adelaide: The ABAC Scheme Limited; 2014 [cited 2017 Jun 7]. Available from: www.abac.org.au/ wp-content/uploads/2014/06/ABAC-Responsible-AlcoholMarketing-Code-30-4-14.pdf

15. Australian Securities \& Investments Commission. Current and historical company extract: The ABAC Scheme Limited. Received 2015 Dec 17.

16. The ABAC Scheme Limited. Adelaide: The ABAC Scheme Limited. About the ABAC Scheme; 2016 [cited 2016 Dec 5]; [about 3 screens]. Available from: www.abac.org.au/about 
17. AMR Australia. AMR National Omnibus: McCusker Centre for Action on Alcohol and Youth. Perth: McCusker Centre for Action on Alcohol and Youth; 2015 [cited 2017 Jun 7]. Available from: www.mcaay.org.au/assets/publications/ market-research-reports/amr-omnibus_mcaay_alcoholreport_finalv3_080715.pdf

18. Wise M. The role of advocacy in promoting health. Promot Educ. 2001;8(2):69-74.

19. Bava S, Tapert S. Adolescent brain development and the risk for alcohol and other drug problems. Neuropsychol Rev. 2010;20(4):398-413.

20. Pettigrew S, Johnson R, Daube M. Introducing and applying a new Australian alcohol advertising code. J Public Aff. 2013;13(1):72-83.

21. Hicks R. Self-appointed alcohol ad watchdog upholds 9 in 10 cases; AANA slams 'PR stunt' for falsely generating complaints. Mumbrella. 2013 Jan 23 [cited 2017 May 22]; [about 3 screens]. Available from: www.mumbrella.com.au/ booze-ad-watchdog-more-than-90-of-australian-boozeads-should-be-banned-135115

22. Taylor F. Alcohol advertising in Australia. National Liquor News. 2017 May;36(4):13.

23. Alcohol Advertising Review Board. Perth: McCusker Centre for Action on Alcohol and Youth; 2016. News; 2016 [cited 2016 Dec 5]; [about 2 screens]. Available from: www. alcoholadreview.com.au/news

24. The ABAC Scheme Limited. The ABAC Scheme Annual Report 2012. Adelaide: The ABAC Scheme Limited; 2013 [cited 2016 Dec 5]. Available from: www.abac.org.au/wpcontent/uploads/2013/06/ABAC_AR_12_Final.pdf
25. The ABAC Sheme Limited. The ABAC Scheme Annual Report 2015. Adelaide: The ABAC Scheme Limited; 2016 [cited 2016 Dec 5]. Available from: www.abac.org.au/wpcontent/uploads/2016/03/ABAC_AR_15_3r.pdf

26. Government of South Australia. Adelaide: Government of South Australia; 2016. Media release, Transport and Infrastructure Minister Stephen Mullighan: alcohol advertising to be banned on public transport; 2016 Aug 19 [cited 2016 Dec 5]; [about 2 screens]. Available from: www.premier.sa.gov.au/index.php/stephen-mullighannews-releases/1036-alcohol-advertising-to-be-banned-onpublic-transport

27. Mark McGowan, WA Labor Leader. Perth: WA Labor; 2017. WA Labor will ban alcohol advertising on public transport; 2017 Feb 15 [cited 2017 May 5]; [about 2 screens]. Available from: www.markmcgowan.com.au/news/walabor-will-ban-alcohol-advertising-on-public-transport-1323

28. Jones S, Francis K, Gordon C. 'It's like a drink you'd have before you go to party': analysis of a Vodka Cruiser advertising campaign. Drug Alcohol Rev. 2017.

29. Pan American Health Organization (PAHO). PAHO meeting on alcohol marketing regulation: final report. Washington, DC: PAHO; 2016 [cited 2017 Jun 7]. Available from: iris. paho.org/xmlui/bitstream/handle/123456789/28424/ PAHONMH16001_eng.pdf?sequence=1\&isAllowed=y

30. Paukštè E, Liutkutè V, Štelemèkas M, Midttun NG, Veryga A. Overturn of the proposed alcohol advertising ban in Lithuania. Addiction. 2014;109(5):711-19.

31. Vendrame A. When evidence is not enough: a case study on alcohol marketing legislation in Brazil. Addiction. 2017;112 Suppl 1:81-5.

\section{Copyright: (c) (i) (2) (2)}

(C) 2017 Pierce et al. This article is licensed under the Creative Commons Attribution-NonCommercial-ShareAlike 4.0 International Licence, which allows others to redistribute, adapt and share this work non-commercially provided they attribute the work and any adapted version of it is distributed under the same Creative Commons licence terms. See: www.creativecommons.org/licenses/by-nc-sa/4.0/ 